exhilarating reading, and the pictures not only illustrate the text, but drive home the lesson, sometimes with irresistible force. To the author science is the basis of healthy life and successful industry. The child is led to ask and answer questions; his appetite is whetted, but never satiated, and he is taught to look for scientific guidance to the State Experimental Station or the proper Government Department, the doors of which (in America) are always open to the inquiries even of children. The school has its proper relation, in some ways almost subordinate, to home and environment in the education of the child. If dollars are often mentioned, it is because they are a measure of the success of each worker in contributing to the well-being of the community. Among some pithy maxims in the preface the following may be commended to teachers: "Do not let such matters as an expensive fence prevent gardening. Get along without the fence. A radish more or less will cut no figure."

Is Venus Inhabited? By C. E. Housden. Pp. 39. (London: Longmans, Green and Co., I9I5.) Price Is. $6 d$. net.

THE uninhabitability of most of the worlds of our system-the sun and moon, Mercury, and the giant planets-is practically assured. Our nearest neighbours, Venus and Mars, remain doubtful; speculation as to life on these worlds is natural and quite legitimate, provided it does not claim greater assurance than the evidence warrants.

Mr. Housden is an enthusiastic adherent of Prof. Lowell's views, and has already written "The Riddle of Mars," supporting the artificial nature of its canal system. He now deals with Venus, assuming the 225 -day rotation, and the reality of the spoke-like markings drawn by Lowell. The great heat on the day hemisphere causes convection currents, which deposit the moisture as ice and snow just inside the dark hemisphere, whence some of it is supposed to flow in the form of glaciers into the day hemisphere. He supposes that the zone of this hemisphere where the sun is low is inhabited by intelligent beings, who pump the water back along several conduits (Lowell's spoke markings). He claims to reconcile the contradictory conclusions $(\mathrm{I}$ ) that the 225 -day rotation would precipitate all moisture on the dark side, and (2) that the bright side is largely cloud-covered. But he has built a large superstructure on a slender basis of observed fact.

The Romance of the Spanish Main. By Norman J. Davidson. Pp. 3r3. (London: Seeley, Service and Co., Ltd., r9i6.) Price $5^{s}$.

THIs "Record of the most daring deeds of some of the most famous adventurers, buccaneers, filibusters, and pirates in the western seas," as the sub-title describes the volume, will fascinate boy readers and incidentally teach them much history and a helpful amount of geography, especially if they will trace the various voyages described on a good map. The book is well illustrated and attractively bound.

\author{
LETTERS TO THE EDITOR.
}

[The Editor does not hold himself responsible for opinions expressed by his correspondents. Neither can he undertake to return, or to correspond with the zoriters of, rejected manuscripts intended for this or any other part of. NATURE. No notice is taken of anonymous communications.]

\section{Pre-Columbian Representations of the Elephant in America.}

MORE than sixty years ago, in his "Incidents of Travel in Central America," Stephens directed attention to an elaborately carved "idol" at Copan, and stated that "the two ornaments at the top look like the trunks of elephants, an animal unknown in that country."

No one who looks at the accompanying tracing, which I have taken from Dr. A. P. Maudslay's mag. nificent atlas of photographs and drawings of the Central American monuments (Godman and Salvin's "Biologia Centrali-Americana," Archæology, plate xxxiv.), should have any doubt about the justification for Stephens's comment. Moreover, the outline of the head is so accurately drawn as to enable the zoologist to identify the original model for the design as the Indian species of elephant. It is equally clear that the sculptor of the monument was not familiar with the actual animal, for, according to Drs. Maudslay and Seler, he has mistaken the eye for the nostril, and the auditory meatus for $\mathrm{th} \mathrm{e}$ eye, and represented the tusk (note its relation to the lower lip) and the ventral surface of the trunk in a con-

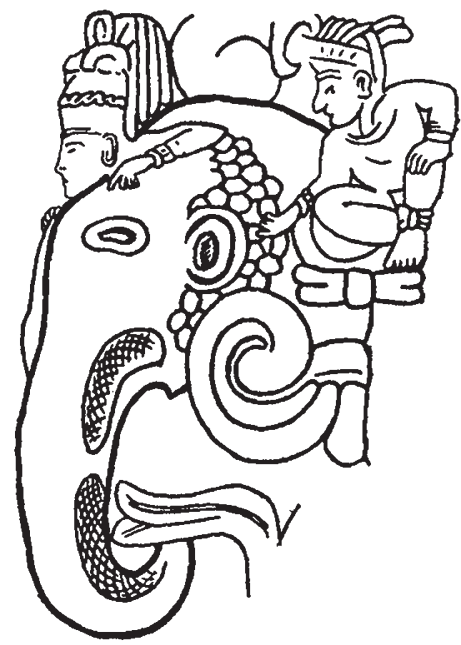

ventionalised manner, without any adequate realisation of the true nature of the features he was modelling.

Certain early Chinese craftsmen adopted a similar convention in their representation of the elephant's tusk and the ventral aspect of the trunk (see, for example, "Chinese Art," vol. ii., Fig. 55, Victoria and Albert Museum Handbooks).

Having converted the auditory meatus into an eye the sculptor had to deal with the auditory pinna, the meaning of which no doubt was a puzzle to him. $\mathrm{He}$ resolved these difficulties by converting it into a geometrical pattern, which, however, he was careful to restrict to the area occupied by the relatively small pinna that is distinctive of the Indian species of elephant. (In the representation of elephants on a beautiful Chinese vase of the Ming period, now in the Victoria and Albert Museum, the posterior border of the pinna is lobulated, and suggests a transition to the geometrical pattern of the Copan design.)

The designer also lost his bearings when he came to deal with the turbaned rider of the elephant. No doubt in the original model the rider's leg was obscured by the pinna; but in the Copan sculpture he has lost his trunk also.

All these features go to prove quite conclusively 